\title{
Emotional face recognition in male adolescents with autism spectrum disorder or disruptive behavior disorder: an eye-tracking study
}

\author{
C. C. A. H. Bours ${ }^{1}$ (1) M. J. Bakker-Huvenaars ${ }^{1}$ - J. Tramper ${ }^{2} \cdot$ N. Bielczyk ${ }^{1} \cdot$ F. Scheepers ${ }^{3} \cdot$ K. S. Nijhof $f^{6,7}$. \\ A. N. Baanders ${ }^{5}$. N. N. J. Lambregts-Rommelse ${ }^{4,8} \cdot$ P. Medendorp ${ }^{2}$ - J. C. Glennon ${ }^{1}$ - J. K. Buitelaar ${ }^{1,4}$
}

Received: 20 December 2017 / Accepted: 22 May 2018 / Published online: 19 June 2018

(c) The Author(s) 2018

\begin{abstract}
Autism Spectrum Disorder (ASD), Oppositional Defiant Disorder (ODD), and Conduct Disorder (CD) are often associated with emotion recognition difficulties. This is the first eye-tracking study to examine emotional face recognition (i.e., gazing behavior) in a direct comparison of male adolescents with Autism Spectrum Disorder or Oppositional Defiant Disorder/ Conduct Disorder, and typically developing (TD) individuals. We also investigate the role of psychopathic traits, callousunemotional (CU) traits, and subtypes of aggressive behavior in emotional face recognition. A total of 122 male adolescents $(N=50 \mathrm{ASD}, N=44 \mathrm{ODD} / \mathrm{CD}$, and $N=28 \mathrm{TD})$ aged $12-19$ years $(M=15.4$ years, $\mathrm{SD}=1.9)$ were included in the current study for the eye-tracking experiment. Participants were presented with neutral and emotional faces using a Tobii 1750 eye-tracking monitor to record gaze behavior. Our main dependent eye-tracking variables were: (1) fixation duration to the eyes of a face and (2) time to the first fixation to the eyes. Since distributions of eye-tracking variables were not completely Gaussian, non-parametric tests were chosen to investigate gaze behavior across the diagnostic groups with Autism Spectrum Disorder, Oppositional Defiant Disorder/Conduct Disorder, and Typically Developing individuals. Furthermore, we used Spearman correlations to investigate the links with psychopathy, callous, and unemotional traits and subtypes of aggression as assessed by questionnaires. The relative total fixation duration to the eyes was decreased in both the Autism Spectrum Disorder group and the Oppositional Defiant Disorder/Conduct Disorder group for several emotional expressions. In both the Autism Spectrum Disorder and the Oppositional Defiant Disorder/Conduct Disorder group, increased time to first fixation on the eyes of fearful faces only was nominally significant. The time to first fixation on the eyes was nominally correlated with psychopathic traits and proactive aggression. The current findings do not support strong claims for differential cross-disorder eye-gazing deficits and for a role of shared underlying psychopathic traits, callous-unemotional traits, and aggression subtypes. Our data provide valuable and novel insights into gaze timing distributions when looking at the eyes of a fearful face.
\end{abstract}

Keywords Autism spectrum disorder · Conduct disorder · Oppositional defiant disorder · Psychopathy · Eye-tracking · Callous and unemotional traits · Aggression

\section{Introduction}

C. C. A. H. Bours and M. J. Bakker-Huvenaars contributed equally to this work.

This article is part of the focused issue 'Conduct Disorder and Aggressive Behaviour in Children and Adolescents'.

Electronic supplementary material The online version of this article (https://doi.org/10.1007/s00787-018-1174-4) contains supplementary material, which is available to authorized users.

C. C. A. H. Bours

carstenbours@gmail.com

Extended author information available on the last page of the article
When communicating with others, non-verbal communication modalities such as body movements, hand gestures, and facial expressions yield essential information, in addition to verbal communication. Decoding facial expressions is one of the most efficient ways for understanding others' emotions and feelings. Individuals with psychiatric disorders as Autism Spectrum Disorder (ASD), Oppositional Defiant Disorder (ODD), and Conduct Disorder (CD) exhibit deficits in regulating emotions and problems inhibiting aggressive tendencies $[45,46]$. This may in turn explain dysfunctions in interpreting emotions of facial expressions. ASD are early 
onset neurodevelopmental disorders defined by core impairments in social interaction and verbal and non-verbal communication, stereotyped and restricted patterns of interest and activity, and abnormal sensory processing according to DSM-5 criteria [1]. ODD is characterized by angry and irritable mood, and argumentative, defiant, and disobedient behavioral patterns. CD is characterized by a pattern of aggressive, destructive, and/or deceitful behaviors that violate the rights of others according to the Diagnostic and Statistical Manual of Mental Disorders (DSM-5) criteria (APA, [1]. In this paper, we will combine ODD and CD into one diagnostic group, since both disorders are closely linked neurodevelopmental disorders of which ODD is either prodromal to $\mathrm{CD}$ or a subsyndromal form of $\mathrm{CD}$ [9]. The rationale for comparing these two distinct diagnostic cohorts (ASD versus ODD/CD) is that both involve social/communication problems and deficits in empathy (related to cognitive and emotional empathy, respectively).

In the latest version of the DSM-5, callous-unemotional (CU) traits were added as a specifier for a more severe form of CD labeled as having 'limited prosocial emotions' [1]. This form of $\mathrm{CD}$ is particularly associated with reductions in empathy when responding to fear, sadness, pain, and happiness of others [12]. ASD has also been associated with dysfunctional empathic functioning $[1,44,73]$ and with increased levels of CU traits [55]. However, commonly deployed diagnostic questionnaires for ASD lack specificity to probe for $\mathrm{CU}$ traits, the relationship remains elusive. Nevertheless, empathy regulation is defined by two different constructs, namely (1) cognitive empathy (i.e., the ability to understand another's feelings) and (2) emotional empathy (i.e., the experience of emotion, elicited by an emotional stimulus) [27].

Individuals with ASD often appear to have cognitive empathy deficits, but demonstrate average levels of emotional empathy $[27,49,76]$. In contrast, those with behavioral disorders (CD and ODD) show the opposite pattern (e.g., $[16,13])$. Looking at facial emotion recognition from a behavioral perspective, no significant differences were detected when comparing ASD adolescent individuals to $\mathrm{CD}$ and TD individuals [51].

Eye tracking in ASD reports inconsistent findings regarding gazing at emotional faces. For an extensive meta-analysis and a summary of the reported differences during development, see [21, 41, 64]. The variation in reported results may partly be due to the variability in the methods utilised to study eye gazing in emotion recognition paradigms. Studies differ on their use of table-mounted remote eye-tracking devices or head-mounted ones. They also differ on their use of static and dynamic facial stimuli and the core characteristics of the faces (e.g., gender, intensity of emotions, and the appearance of the faces). In addition, many methodological issues cannot be properly controlled for which introduces additional heterogeneity. Studies differ in sampling frequencies of eye-tracking devices, the selection strategy of areas of interest, fixation classification filters, and the informed use of parametric or non-parametric statistical tests. Some of the earlier eye-tracking studies in adults and adolescents with ASD reported that less attention was paid to the eyes and other core features of faces [68] or focused more on the mouth and less on the eyes $[53,60]$. Other studies confirmed that adults with ASD gazed less at the eye region while exploring a face [25, 43]. In contrast, more recent studies have not observed significant differences between individuals with ASD and typically developing youth in eyegazing behavior [78, 82, 83]. More broadly speaking, gazing at the eyes can facilitate more accurate and faster responding to several emotions like fear, surprise, and disgust [6] and thus enable better social interaction. Numerous experimental studies have found strong evidence for reduced accuracy in identifying negative emotions in individuals with ASD [4, $7,25,48,84]$, although there is no consensus in the field.

Overall, insufficient gazing to the eyes can lead to impaired emotional recognition which may influence disruptive behaviors and increase social anxiety in individuals with ASD [25].

Antisocial behavior is also associated with poor recognition and processing of fearful faces [56]. Recent studies confirm impaired recognition of multiple emotions (anger, fear, and happiness) in adolescents with CD relative to TD individuals $[35,36,80]$. Furthermore, children with greater behavioral problems (as indexed through the Psychopathy Screening device) also showed poorer recognition of angry, sad, and fearful facial expressions [10]. Those children and adolescents with both $\mathrm{CD}$ and high $\mathrm{CU}$ traits showed more pervasive impairments in emotional recognition than those with low CU traits [33,36]. Recently, the first well-powered eye-tracking study on a large cohort of male and female adolescents with CD has been published. Martin-Key et al. [57] used an emotion recognition task with both static and dynamic morphed faces. They found that male adolescents fixated less on the eyes when viewing fearful and sad expressions. Although the differences were considered small, the authors suggest that behaviorally detected emotion recognition deficits were not mediated by abnormal fixation patterns [57].

ASD symptoms may moderate the relationship between CU traits and aspects of emotional empathy [70]. Pijper et al. [70] suggest that CU traits are inversely related to empathic sadness at low levels of ASD symptoms, while others document it only for higher levels of ASD symptoms [65]. Psychopathic traits seem to predict lower numbers of fixations and fixation durations to the eye region in fearful faces in TD male adolescents [29]. Individuals with ASD also have elevated levels of aggressive behavior compared to TD individuals [47], although aggression is not a core symptom of 
ASD and is typically less severe in ASD than ODD/CD [3]. For $\mathrm{CD}$ and ODD, both proactive and reactive aggression are considered hallmarks of the disorder [17], and the relation of subtype of aggression and eye-tracking patterns of emotional face processing is unclear. From a broader perspective, it seems that many concepts (i.e., psychopathic traits, $\mathrm{CU}$ traits, and subtypes of aggression) in different disorders (i.e., ASD, ODD, and CD) seem to be interlinked and associated with each other, while actual direct links remain elusive and a direct comparison is missing.

In summary, eye-tracking data in the literature related to emotional face processing are inconsistent in ASD and studies have not been properly replicated in large wellphenotyped psychiatric cohorts for CD and ODD. These relationships still remain elusive and the field suffers from inconsistency in approach to data collection and analyses and using fairly small sample sizes [41]. Our relatively large cohort (total $N=122 ; \mathrm{ASD}=52, \mathrm{ODD} / \mathrm{CD}=42, \mathrm{TD}=28$ ) consisting of male adolescents enables us to examine the common and unique eye-tracking patterns of emotional face processing in individuals with either ASD, ODD, or $\mathrm{CD}$, in comparison with $\mathrm{TD}$, and explore the possible modulatory role of CU traits, psychopathic traits and subtypes of aggression. We hypothesize that high CU traits, high psychopathic traits, and heightened proactive and reactive aggression will be associated with less time spent to the eye region for negative emotions (e.g., sadness, fear, and anger) in both male adolescents with ASD or CD/ODD. Furthermore, we hypothesize that both male adolescents with ASD and ODD/ $\mathrm{CD}$ will show similar differences on the time to first fixation to the eye region of an emotional face.

\section{Methods}

\section{Recruitment of participants}

Initially, 423 individuals were approached to participate in a larger study on empathy (CU2 study). Individuals with an ODD/CD diagnosis were approached via institutes specialized in severe juvenile psychiatric problems (Karakter, Child and Adolescent Psychiatry) or severe disruptive behavior problems (De Hoenderloo Group, Otto Gerhard Heldring Foundation, and Woodbrookers). Individuals with ASD were recruited via information leaflets that were sent to families by the Dutch federation of Autism (NVA). The typically developing individuals' control groups were recruited via leaflets that were sent to a community sample. These individuals were selected on the basis of their geographical location. The recruitment period lasted from April 2011 to September 2014. Of those approached, 265 did not respond or were not interested to participate. Of the 158 that were interested in participation, 18 did not meet the inclusion criteria (see below for more information). Two participants did not obtain consent from a legally appointed guardian and 6 participants were not able to participate due to their personal situation. In total, 132 were included for the broader CU2 study. Of the 132 participants, 6 participants did not undergo the extensive eye-tracking battery. Of the 126 participants, 4 participants had to be excluded based on exclusion criteria for eye-tracking data quality. Thus, all the presented data are from the 122 participants (50 with ASD, 44 with ODD or CD and 28 TD individuals). All participants were male adolescents [age range (12-19 years old, mean age $=15.26$ years, $\mathrm{SD}=1.9]$.

Main participant and demographic characteristics are summarized in Table 1.

The difference between the number of participants initially approached and the final inclusion in this eye-tracking study is considerable large. In many cases, participants with ODD/CD were not interested in participating in an extensive clinical study. Many had behavioral problems and were often not in a position to participate. There were restrictions to leave closed institutions or their personal situation did not allow participation. Here, one can think of the occurrence of violent and/or oppositional incidents, escape attempts, and (temporary) dysfunctional relationships with their caregivers.

\section{Inclusion and exclusion criteria for participation}

All participants who were recruited from clinical institutes obtained a clinical ASD or ODD/CD diagnosis prior to the study. Clinical diagnoses (ODD/CD and ASD) were established according to the DSM-IV-TR criteria [5] by a multidisciplinary team (experienced psychiatrist and psychologist). In a large proportion of our ASD participants, the clinical diagnoses were confirmed by clinical scores on the 'golden standard' of the ADOS and ADI, although this was not a fixed criterion for inclusion in this study.

They both gathered information and reviewed (prior) clinical records and information provided by schools and other agencies involved in the care of the adolescent. This workflow ensured that the proper clinical diagnosis was confirmed, before individuals were included in the current study. This is a robust and more reliable approach compared to only using structured interviews for the allocation of individuals to clinical groups [54].

For all the three groups, caretakers (i.e., biological parents or legal guardians) were asked to fill out a digital version of the National Institute of Mental Health Diagnostic Interview Schedule for Children (DISC-IV; [77]). Parents and/or caregivers had to complete the following sections of the DISC-IV: Attention-Deficit/Hyperactivity Disorder, ODD, CD, Tic Disorder, alcohol, marihuana, and other drug use. The social communication questionnaire (SCQ) was 
Table 1 Characteristics of the study population $(N=122)$

\begin{tabular}{|c|c|c|c|c|c|c|c|c|c|}
\hline & \multicolumn{2}{|c|}{ Total group } & \multicolumn{2}{|l|}{ TD } & \multicolumn{2}{|c|}{ ODD/CD } & \multicolumn{2}{|l|}{ ASD } & \multirow[t]{2}{*}{ Contrasts } \\
\hline & $M$ & $\pm \mathrm{SD}$ & $M$ & $\pm \mathrm{SD}$ & $M$ & $\pm \mathrm{SD}$ & $M$ & $\pm \mathrm{SD}$ & \\
\hline Age (years) & 15.2 & 1.9 & 15.9 & 1.8 & 15.2 & 1.7 & 14.9 & 2.0 & n.s. \\
\hline FSIQ & 101.1 & 10.5 & 106.3 & 9.5 & 94.9 & 6.9 & 103.4 & 11.1 & $\mathrm{ODD} / \mathrm{CD}<\mathrm{ASD}=\mathrm{TD}^{* * *}$ \\
\hline VIQ & 101.9 & 13.6 & 108.5 & 12.9 & 92.1 & 11.1 & 104.8 & 12.0 & $\mathrm{ODD} / \mathrm{CD}<\mathrm{ASD}=\mathrm{TD} * * *$ \\
\hline PIQ & 101.1 & 14.0 & 105.4 & 15.1 & 96.8 & 11.4 & 101.6 & 14.4 & ns \\
\hline \multicolumn{10}{|l|}{ ICU total scores } \\
\hline ICU self-rated & 26.8 & 8.8 & 23.6 & 6.3 & 31.0 & 10.0 & 24.9 & 7.6 & $\mathrm{ODD} / \mathrm{CD}>\mathrm{ASD}=\mathrm{TD} * * *$ \\
\hline ICU parent-rated & 28.8 & 11.3 & 17.0 & 7.1 & 38.9 & 7.7 & 28.1 & 8.3 & $\mathrm{ODD} / \mathrm{CD}>\mathrm{ASD}>\mathrm{TD} * * *$ \\
\hline \multicolumn{10}{|l|}{ YPI self-rated scores } \\
\hline Total score & 93.55 & 23.1 & 82.21 & 17.1 & 106.87 & 23.2 & 88.45 & 20.6 & $\mathrm{ODD} / \mathrm{CD}>\mathrm{ASD}=\mathrm{TD} * * *$ \\
\hline CU subscale & 27.22 & 6.7 & 23.75 & 5.3 & 30.80 & 6.9 & 26.09 & 5.8 & $\mathrm{ODD} / \mathrm{CD}>\mathrm{ASD}=\mathrm{TD}^{* * *}$ \\
\hline \multicolumn{10}{|l|}{ RPQ self-rated scores } \\
\hline Total score & 13.46 & 8.4 & 7.64 & 4.3 & 19.30 & 8.4 & 11.31 & 7.0 & $\mathrm{ODD} / \mathrm{CD}>\mathrm{TD}=\mathrm{ASD} * * *$ \\
\hline Reactive & 9.54 & 5.2 & 6.00 & 3.3 & 12.30 & 4.8 & 8.84 & 5.1 & $\mathrm{ODD} / \mathrm{CD}>\mathrm{ASD} * * *>\mathrm{TD} *$ \\
\hline Proactive & 3.79 & 3.9 & 1.64 & 1.8 & 6.71 & 4.6 & 2.34 & 2.5 & $\mathrm{ODD} / \mathrm{CD}>\mathrm{TD}=\mathrm{ASD} * * *$ \\
\hline \multirow[t]{4}{*}{ SCQ } & 11.38 & 7.1 & 3.96 & 3.1 & 11.24 & 6.0 & 15.64 & 5.8 & $\mathrm{ASD}>\mathrm{ODD} / \mathrm{CD}<\mathrm{TD}^{* * *}$ \\
\hline & \multicolumn{2}{|c|}{ Total group } & \multicolumn{2}{|l|}{ TD } & \multicolumn{2}{|c|}{$\mathrm{ODD} / \mathrm{CD}$} & \multicolumn{2}{|l|}{ ASD } & \multirow[t]{3}{*}{ Contrasts } \\
\hline & $n$ & $\%$ & $n$ & $\%$ & $n$ & $\%$ & $n$ & $\%$ & \\
\hline & 122 & 100.0 & 28 & 23.0 & 44 & 36.0 & 50 & 41.0 & \\
\hline \multicolumn{10}{|l|}{ Institute } \\
\hline Child and adolescent psychiatry & 50 & 41 & 0 & 0 & 9 & 20.5 & 41 & 82 & \\
\hline Youth welfare & 36 & 30 & 0 & 0 & 35 & 79.5 & 1 & 2 & \\
\hline Dutch association for autism & 8 & 6 & 0 & 0 & 0 & 0 & 8 & 16 & \\
\hline \multicolumn{10}{|l|}{ Comorbidity } \\
\hline ADHD & 50 & 41 & 0 & 0 & 28 & 63.6 & 22 & 44 & $\mathrm{ODD} / \mathrm{CD}>\mathrm{ASD}>\mathrm{TD} * *$ \\
\hline None & 64 & 52 & 26 & 93 & 10 & 22.7 & 27 & 54 & \\
\hline Missing & 9 & 7 & 2 & 7 & 6 & 13.7 & 1 & 2 & \\
\hline \multicolumn{10}{|l|}{ Medication } \\
\hline Yes & 48 & 55.8 & 0 & 0 & 17 & 38.6 & 31 & 62.0 & $\mathrm{ASD}>\mathrm{ODD} / \mathrm{CD}>\mathrm{TD}^{*}$ \\
\hline No & 68 & 39.3 & 28 & 100 & 21 & 47.8 & 19 & 38.0 & \\
\hline Missing & 6 & 4.9 & 0 & 0 & 6 & 13.6 & 0 & 0 & \\
\hline \multicolumn{10}{|l|}{ Ethnicity parents ${ }^{\mathrm{a}},(\%)$} \\
\hline Both Caucasian & 96 & 78.7 & 26 & 92.9 & 21 & 50.0 & 49 & 94.2 & $\mathrm{ODD} / \mathrm{CD}<\mathrm{ASD}=\mathrm{TD} * * *$ \\
\hline Caucasian and other & 11 & 9.1 & 2 & 7.1 & 6 & 14.2 & 3 & 5.8 & \\
\hline Both are unknown & 4 & 3.3 & 0 & 0 & 4 & 9.5 & 0 & 0 & \\
\hline \multicolumn{10}{|c|}{ Highest level of education parents ${ }^{\mathrm{b}},(\%)$} \\
\hline Lower & 7 & 5.7 & 0 & 0 & 4 & 9.5 & 3 & 5.8 & \\
\hline Middle & 38 & 31.1 & 3 & 10.7 & 15 & 35.7 & 20 & 38.5 & \\
\hline Higher & 63 & 51.6 & 25 & 89.3 & 10 & 23.8 & 28 & 53.8 & $\mathrm{ODD} / \mathrm{CD}<\mathrm{ASD}<\mathrm{TD}^{*}$ \\
\hline
\end{tabular}

$F S I Q$ full-scale IQ, ICU callous-unemotional traits based on the inventory of callousness-unemotional traits. YPI youth psychopathic trait inventory. $R P Q$ reactive and proactive questionnaire. $S C Q$ social communication questionnaire. $T D$ typical developing individuals, $A S D$ autism spectrum disorder, $O D D / C D$ oppositional defiant disorder/conduct disorder, $n a$ : not assessed, $n s$ not significant

$p$ value: $* p<0.05 ; * * p<0.01, * * * p<0.001$

${ }^{a}$ Ethnicity parents: data based on two parents

${ }^{\mathrm{b}}$ Highest level of education parents: data based on family level 
used as an instrument to assess ASD characteristics across the three groups (ASD, ODD/CD, and TD). For the typically developing group, the absence of a clinical psychiatric diagnosis was assessed based on the DISC-IV parent interview [77]. The outcomes of the DISC-IV and the SCQ were evaluated by an experienced child and adolescent psychiatrist $(\mathrm{PH})$ and psychologist (MJB).

We excluded participants who fulfilled one or more of the exclusion criteria (a) a combined diagnosis of ASD and CD/ ODD, (b) an estimated total IQ <80); and/or (c) suffering from a condition which may affect neurological or cognitive functioning, such as schizophrenia, bipolar disorder, alcohol and/or drugs dependency, language disorder (e.g., dyslexia), epilepsy, and the presence of tics. The TD individuals were not allowed to have a clinically established psychiatric diagnosis to participate. The other in- and exclusion criteria were the same as for the clinical groups. Participants with a diagnosis of ODD or CD from the CU2 project were grouped together in this study, because both disorders are on a spectrum of behavior problems and aggressive tendencies. In addition, the ODD/CD group included only a few CD participants to be handled as a stand-alone group.

\section{Medication use}

The use of non-psychotropic and anti-depressant medication was allowed for the inclusion in the study. If possible, psychotropic medication (i.e., antipsychotics, stimulants, and atomoxetine) was stopped prior to testing. Stimulants were discontinued for at least $24 \mathrm{~h}$ prior to participation and antipsychotics for at least $72 \mathrm{~h}$. Only in cases, when a health care professional judged the discontinuation to have potential severe detrimental effects, the medication was not stopped. In total, 9 participants with ODD/CD and 8 participants with ASD were still on medication during the testing days.

\section{Cognitive assessments}

Participants were required to have a minimum average estimated total full-scale intelligence quotient (FSIQ) IQ of $\geq 80$. The FSIQ was estimated using four subtests of the Dutch version of the Wechsler Intelligence Scale for Children (WISC-III): Similarities, Block Design Picture Completion, and Vocabulary [85]. These WISC-III subtests are known to be highly correlated ( $r=0.90-0.95)$ with full-scale IQ [40]. For the participants that were 16 years or older, the Wechsler Adult Intelligence Scale III (WAIS-III) was administered [86].

\section{Procedures}

A short telephone screening and, subsequently, screening questionnaires were used to verify if families could participate. Those families were invited to visit one of the participating clinics. Testing of the participants took place in a quiet room at the test location. Experimenters used stimulus deprived rooms to limit the influence of distraction. Participants were given short breaks and received a financial compensation (vouchers of $€ 20.00$ ) for this test administration.

\section{Ethical approval}

This study was approved by the Dutch Central Committee on Research involving Human Subjects, protocol number NL26773.000.09 (Centrale Commissie Mensgebonden Onderzoek; CCMO). Both adolescents (if 12 years of age and older) and their legally appointed guardian provided written informed consent.

\section{Description of clinical measures}

\section{Social communication questionnaire (SCQ)}

The social communication questionnaire is a 40-item parentreport questionnaire that investigates ASD characteristics on a binary scale (yes/no). The questionnaire contains 19 items on current behavior and 20 items on the period when the child was 4-5 years old [75]. A cut-off score of $>10$ was used as a positive screening outcome on ASD characteristics. TD participants could only be included when they did not have a clinical score on the parent-rated SCQ (i.e., raw scores of $<10$ ). In calculating the total score, the first item was excluded, because it only probed for sufficient language ability. The English version of the SCQ has a sensitivity ranging between 0.85 and 0.88 and a specificity between 0.72 and $0.78[8,19,20]$. The Cronbach's alpha for the total SCQ score was 0.75 in the final sample.

\section{Inventory of Callous-Unemotional traits (ICU)}

The Inventory of Callous-Unemotional traits (ICU) assesses CU traits in adolescents, divided into three subscales: uncaring, callousness, and unemotional [37]. We used the official Dutch translated version of this questionnaire. Internal consistency of the Dutch ICU was shown to be good [34, 74]. The ICU exists of 12 positively framed items and 12 negatively framed items. Items are rated on a 4-point scale ranging from 0 ('not at all true') to 3 ('definitely true'). The uncaring scale consists of 8 items, the callousness subscale of 11 items, and the unemotional subscale of 5 items. An example of an item on the uncaring scale is ' $I$ am concerned about the feelings of others'. An example item for the callousness scale is: 'I seem very cold and uncaring to others'. Finally, an example of the unemotional scale: 'I do not show my emotions to others'. Subscale scores are calculated by 
summing the individual item scores. The reverse and 'opposite' framing of sentences is taken into account in the scoring. Subsequently, the total score is calculated by summing up the subscale scores. A higher total score reflects a higher levels of CU traits. We administrated both the parent version (legal guardian) and the self-rated version of the ICU. For the final sample, the Cronbach's alpha for the self-report was 0.78 and the Cronbach's alpha for the parent report was 0.90 .

\section{Youth psychopathic trait inventory (YPI)}

The youth psychopathic traits inventory (YPI) is a 50-item self-report questionnaire [2]. It has been designed to assess core psychopathic personality traits for adolescents of 12 years of age and older. It reflects 3 dimensions of psychopathy: the grandiose manipulative, callous-unemotional, and impulsive-irresponsible [24]. Higher YPI total scores reflect the presence of high psychopathic traits. Internal consistency has been reported as 0.94 Cronbach's alpha for the total score of the YPI, 0.82 for the grandiose-manipulative subscale, 0.64 for callous-unemotional subscale, and 0.76 for impulsive-irresponsible subscale.

\section{Reactive and proactive aggression questionnaire (RPQ)}

The Reactive and Proactive Aggression Questionnaire (RPQ) was developed by Raine et al. [71]. In the current study, the Dutch translation of the well-validated 23-item RPQ was used which is designed to probe for reactive and proactive aggression in children and adolescents from the age of 8 years of age and older [22]. The reactive subscale has 11 items. Example questions include: 'He/she gets mad or hit others when they tease him/her' and 'He/she damages things when he/she is mad'. The proactive subscale has 12 items. Example questions for this subscale are: 'He/she damages or breaks things for fun' and 'He/she threatens and bullies other kids'. The questions of the RPQ do not reference to a certain time period in the past or current behavior. Participants just have to report how often they have engaged in particular behaviors. The total score of the RPQ is calculated by summing all items together. The Cronbach's alpha for the RPQ was 0.91 in our final sample.

\section{General study protocol}

Participants and their legal guardians that gave informed consent were screened using the DISC-IV interview device [77]. The information of the DISC-IV was combined with the clinical diagnosis information to allocate participants into the different groups. The participants and their legal guardians were asked to fill out questionnaires (paper and pencil) separately from each other. This could either be at home or at the test location. For the test location, experimenters used a stimulus deprived quiet room. The influence of external noise and distraction was limited. For completing the questionnaires at home, the participants and their legal guardians were asked to sit in a quiet room with as few external distractions as possible.

\section{Task design}

We used an emotional recognition task that consisted of 60 trials with static images of emotional and neutral faces. Each trial always had the same structure: 'fixation cross (1 s)-facial stimulus (6 s)-question-gray screen (3s)'. The rationale behind the presentation of the gray screen was twofold. First, we wanted to avoid the confound of pupil response to the differences in light intensity of the facial stimuli (presented on a black background) and the questions (presented on a white background). Second, the use of the gray screen countered potential 'wash over effects' of gazing at emotional faces and neutral faces and vice versa.

Trials with emotional faces and neutral faces were interleaved. The whole task consisted of two sessions of 30 trials that was interrupted by a short break. Both the sessions had a different order of the presentation of the emotional and neutral faces. All used faces were balanced on gender, ethnicity, and in the adult age range. A set of face stimuli were selected from the online NimStim of Facial Expressions set (available to the scientific community at http://www.macbr ain.org/resources.htm) [81]. The faces differed on the intensity of portrayed emotion from high to low. Both the types of emotion and the portrayed intensity have been previously validated [42]. The Dutch question asked to the participants was presented on the screen and can be translated as 'What kind of emotion did you see?'. The participants always had five answer options: neutral, happy, sad, angry, and fear. The order of the answers on the screen was balanced over the trials.

\section{Data pre-processing}

We exported the fixation data from Tobii studio 2.2.08 and used Matlab 2016B [58] to pre-process the eye-tracking data. We used stringent data exclusion and inclusion criteria. Trials were excluded if there was no fixation data for $25 \%$ or more of the trial duration. At least $1.5 \mathrm{~s}$ of the $6 \mathrm{~s}$ trial duration had to contain valid eye-tracking data. To overcome and counter potential artifacts, we did not take the first $100 \mathrm{~ms}$ of the trail into account for the time to first fixation. In the first $100 \mathrm{~ms}$, it is hard to disentangle 'real fixations' from potential measurement artifacts or limitations of the used apparatus with sampling rate of 50. Moreover, we excluded participants in which $50 \%$ or less of the trials were valid. Applying these criteria led to the exclusion of 4 participants ( 2 participants with ASD and 2 with ODD/CD). 


\section{Normality of distributions}

We investigated the distributions of all our eye-tracking output variables and checked for violations of normality. We used skewness and kurtosis to establish normality values (see supplementary Table 1 for more information). For all three groups and all the eye-tracking variables, normality could not be completely assumed. This led to the choice to use non-parametric statistics such as the Kruskal-Wallis tests [18], non-parametric Mann-Whitney post hoc tests, and Spearman correlations. The Spearman correlations are rank order free and resistant to violations of normality assumptions. In this way, we could ensure that eye-tracking variables in milliseconds would still have biological plausible meaning.

\section{Statistical analysis}

We applied a non-parametric trial-based approach to investigate gazing behavior on the AIO (eyes, mouth, and rest of the image) of emotional and neutral faces [18]. For all our three main eye-tracking variables (total fixation duration, time to first fixation, and percentage total fixation), we used Kruskal-Wallis one-way ANOVA tests (two-tailed, significance level $\alpha=0.05$ ) to test for group differences. For the variable 'time to first fixation' on the eye AIO, we investigated the relative distribution (percentagewise) for all three groups (ASD, ODD/CD, and TD) for values in time bins of $50 \mathrm{~ms}$. To overcome and counter potential artifacts, we did not take the first $100 \mathrm{~ms}$ of the trial into account for the time to first fixation. In the first $100 \mathrm{~ms}$, it is hard to disentangle 'real fixations' from potential measurement limitations of the used apparatus. We ran five tests separately for all the different emotions (anger, sad, fear, and happiness) and neutral faces (see Fig. 1). We applied Bonferroni corrections for multiple testing (two-tailed, significance level, $\alpha=0.01$ ). We performed Mann-Whitney post hoc tests to examine the specific directionality of effects between the groups. The same rationale was followed for all of our eye-tracking variables. For the investigation of behavioral results of the emotion recognition task, we looked at the percentages of correct answers per group and tested for group differences via $t$ tests after $z$ score transformations.

Furthermore, we investigated the correlation (Spearman test, two-tailed, significance level $\alpha=0.05$ ) between eye-gazing pattern for emotional faces with $\mathrm{CU}$ traits (total score of ICU, and YPI CU subscale scores), psychopathic traits (YPI total score), and severity of aggression (RPQ scores for proactive and reactive aggression).

\section{Results}

\section{Descriptive results}

See Table 1 for sample characteristics. The three groups did not differ in age, but significantly differ in estimated full-scale IQ (FSQ). A post hoc test revealed that the FSQ was lowest for the ODD/CD group, and highest in the TD group, while the ASD group scored in between of the two. There was no significant difference between the ASD group and the TD group. The three groups significantly differed on SCQ, post hoc test revealed that the ASD group scored higher than the ODD/CD group. Regarding selfrated $\mathrm{CU}$ traits, the ODD/CD group showed significantly higher CU scores than both the TD and ASD groups, whereas the TD and ASD groups did not differ from each other. Regarding the parent-rated CU traits, the ODD/CD group scored significantly higher than the ASD group, and the ASD group scored significantly higher than the TD group. The three groups differed significantly from each other on aggressive behavior (RPQ total score). A post hoc test showed that the ODD/CD group had significantly higher scores on the RPQ total score then both the ASD
Fig. 1 Distributions of the time to first fixation on the eyes of fearful faces for 100-1000 ms. Timebins are $50 \mathrm{~ms}$ each. $T D$ typically developing individuals, $A S D$ autism spectrum disorder, $O D D$ oppositional defiant disorder, $C D$ conduct disorder

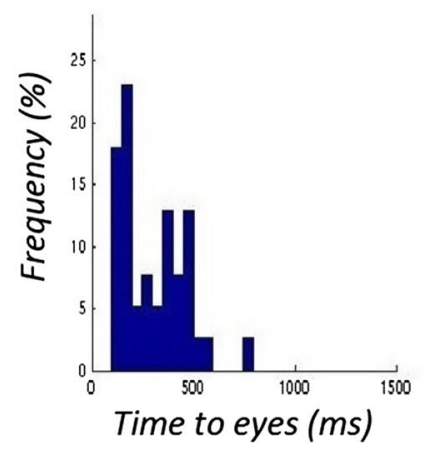

TD

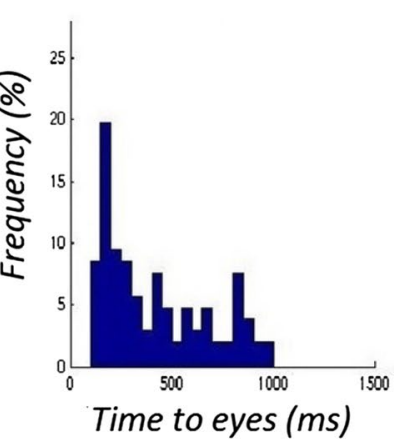

ASD

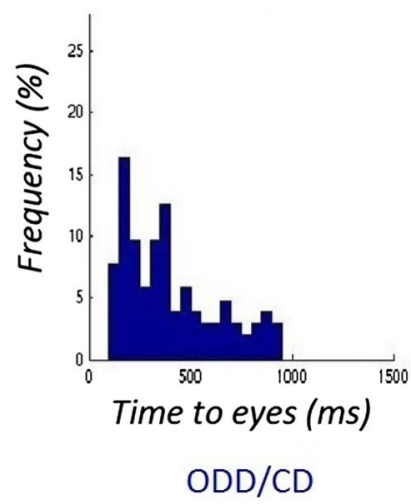


Table 2 Eye-tracking results for gazing at the eyes

\begin{tabular}{lrlrll}
\hline $\begin{array}{l}\text { Total fixation } \\
\text { duration }\end{array}$ & $N$ & $\begin{array}{l}\text { Degrees of } \\
\text { freedom }\end{array}$ & Chi square & Significance & Contrasts post hoc test \\
\hline Anger & 774 & 2 & 511.5 & $p=0.003$ & TD $>$ ODD/CD** \\
Fear & 835 & 2 & 15.1 & $p<0.01$ & TD $>$ ODD/CD** \\
Sad & 816 & 2 & 0.6 & $p=0.74$ & $\mathrm{~ns}$ \\
Happy & 835 & 2 & 15.2 & $p=0.001$ & \\
Neutral & 2866 & 2 & 31.2 & $p<0.001$ & $\mathrm{TD}>\mathrm{ASD}^{* * *}$ TD $>$ ODD/CD*** \\
Time to first fixation & & & & \\
Fear & 248 & 2 & 6.11 & $p=0.047$ & $\mathrm{TD}>$ ASD $=$ ODD/CD* \\
Anger & 222 & 2 & 4.04 & $p=0.1$ & $\mathrm{~ns}$ \\
Sad & 234 & 2 & 2.47 & $p=0.5$ & $\mathrm{~ns}$ \\
Happy & 264 & 2 & 5.79 & $p=0.055$ & $\mathrm{~ns}$ \\
Neutral & 116 & 2 & 3.25 & $p=0.19$ & $\mathrm{~ns}$ \\
\hline
\end{tabular}

$T D$ typically developing individuals, $A S D$ autism spectrum disorder, $O D D$ oppositional defiant disorder, $C D$ conduct disorder

$n s$ not significant, $* p<0.05 ; * * p<0.01, * * * p<0.001$ and the TD groups. The ASD group did not differ from the TD group. Regarding reactive aggression, the ODD/CD group had significantly higher scores than both the ASD and TD groups. The ASD group and the TD group did not differ from each other. Regarding proactive aggression, the ODD/CD group had significantly higher scores than both the ASD and TD groups. The ASD group and the TD group did not differ from each other (Table 2).

\section{Eye-tracking results and behavioral results}

We found a main group effect for relative total fixation time to the eye region for fearful (Kruskal-Wallis one-way

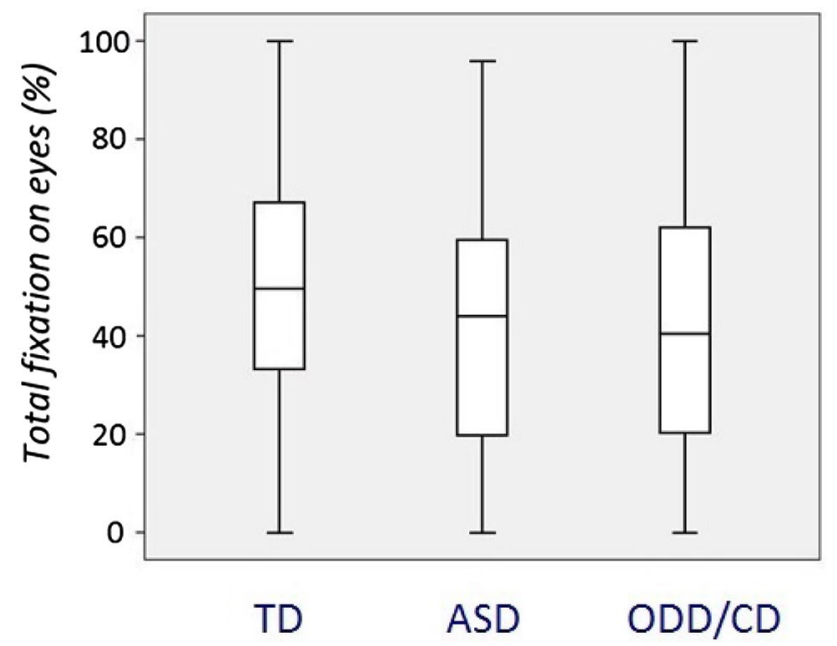

Fig. 2 Percentage of total fixation duration on the eyes of fearful faces. $T D$ typically developing individuals, $A S D$ autism spectrum disorder, $O D D$ oppositional defiant disorder, $C D$ conduct disorder
ANOVA, $\left[\chi^{2}(d f=2, N=835)=15.1, p<0.01\right]$ (presented in Fig. 2), angry $\left[\chi^{2}(d f=2, N=774)=511.5, p<0.01\right]$, happy $\left[\chi^{2}(d f=2, N=835)=15.2, p=0.001\right]$, and neutral faces $\left[\chi^{2}(d f=2, N=2866)=31.2, p<0.001\right]$. The $N$ number is representing the number of trials per emotion per experimental group. When correcting for multiple comparisons via Bonferroni correction $(p=0.05 / 5=0.01)$, these main effects remained significant. Mann-Whitney post hoc tests revealed that the TD group had significantly more fixations to the eye region than the participants with ASD or ODD/CD for fearful, angry, happy, and neutral faces, whereas the ASD and ODD/CD groups did not differ from each other. There was no main group effect for sad faces $\left[\chi^{2}(\mathrm{df}=2, N=819)=0.6, p=0.7\right]$.

We found a main group effect for the time to first fixation towards the eye region for fearful faces [Kruskal-Wallis one-way ANOVA, $\left.\chi^{2}(d f=2, N=248)=6.11, p=0.046\right]$ (Fig. 3). When correcting for multiple comparisons via Bonferroni $(0.05 / 5=0.01)$, this main group effect did not survive.

We performed Mann-Whitney post hoc tests to investigate the directionality of this nominal significant main effect. That revealed that both groups with ASD or ODD/ CD took significantly longer time to first fixate on the eyes of a fearful face, compared to TD participants. We did not find any main group effects on time to first fixation to the eye AIO for sad, angry, happy, and neutral faces.

The behavioral results for the emotion recognition task are presented in Table 3. We looked at the percentages of correct answers and the group differences via $t$ tests via normalized $z$ scores. We found significant differences between the ODD/CD group and the TD group for the happy faces $(p<0.005)$ and sad faces $(p=0.01)$. We also found differences between the ODD/CD group 


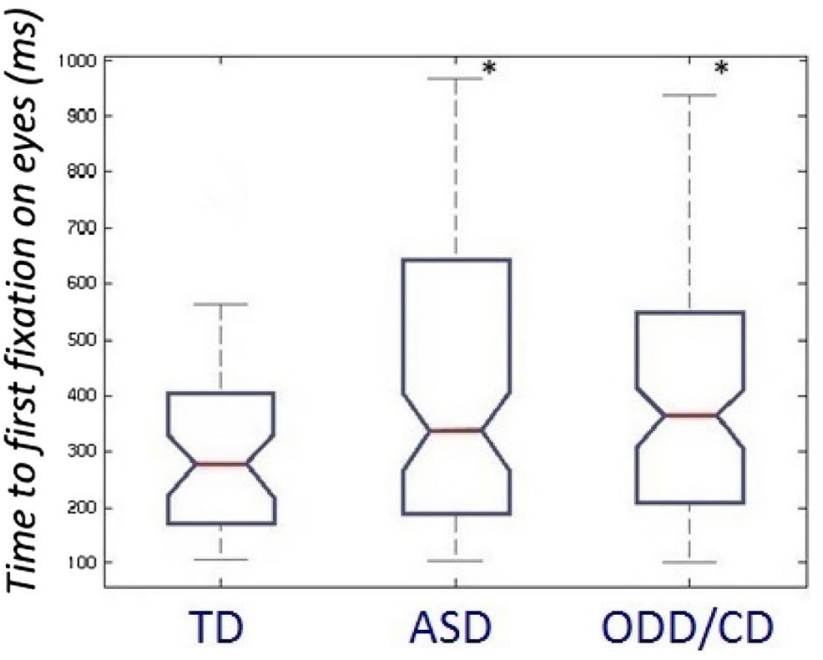

Fig. 3 Time to first fixation in milliseconds on the eyes of fearful faces. $T D$ typically developing individuals, $A S D$ autism spectrum disorder, $O D D$ oppositional defiant disorder, $C D$ conduct disorder

Table 3 Behavioral results of emotion recognition task

\begin{tabular}{llllll}
\hline Emotions & TD & ODD/CD & ASD & Contrast & Significance \\
\hline Neutral & 69.3 & 66.1 & 63.2 & ODD/CD_TD* & $p=0.046$ \\
Angry & 46.6 & 45.5 & 41.0 & & \\
Happy & 96.1 & 91.7 & 90.3 & ODD/CD_TD*** & $p=0.005$ \\
Sad & 59.9 & 52.1 & 46.1 & ODD/CD_TD* & $p=0.01$ \\
& & & & ODD/CD-ASD* & $p=0.03$ \\
Fearful & 84.0 & 80.6 & 75.2 & ODD/CD_ASD* & $p=0.02$ \\
\hline
\end{tabular}

Depicted are the percentages correctly recognized emotional faces The effects are bases on $t$ tests, normalized with z-transformation

$T D$ typically developing individuals, $A S D$ autism spectrum disorder, $O D D$ oppositional defiant disorder, $C D$ conduct disorder

$n s$ not significant, $* p<0.05 ; * * p<0.01$, $* * * p<0.001$

and the ASD group for neutral faces $(p<0.05)$, sad faces $(p=0.03)$, and fearful faces $(p=0.02)$. These are all nominal significants, since only the result for happy faces survives Bonferroni correction $(0.05 / 5=0.01)$.

\section{Correlations of eye-tracking variables and behavioral traits}

Only in the ODD/CD group, we found a nominal significantly negative Spearman correlation between the time to first fixation at the eyes of fearful faces and psychopathic traits $(r=0.35, p=0.02)$ (Fig. 4). When correcting for multiple comparison via Bonferroni correction $(p=0.05 / 5=0.01)$, the Spearman correlation did not survive this correction. In addition, proactive aggression was also negatively correlated $(r=-0.33, p=0.04)$ with time to first fixation to the eyes of fearful faces in the ODD/

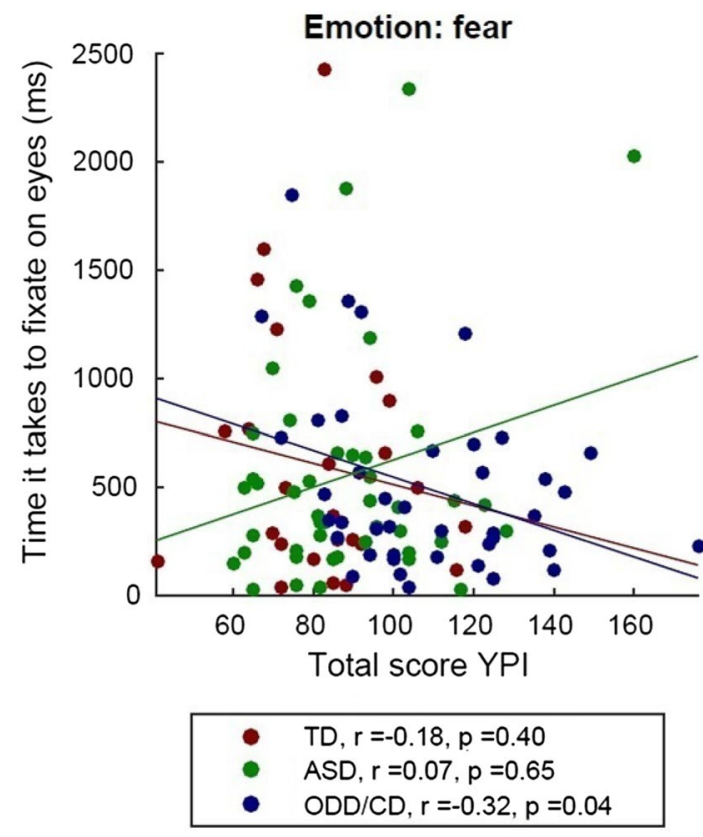

Fig. 4 Spearman correlations between the time to first fixation on the eyes of fearful faces and total score of the YPI. $T D$ typically developing individuals, $A S D$ autism spectrum disorder, $O D D$ oppositional defiant disorder, $C D$ conduct disorder

CD group. When correcting for multiple comparison via Bonferroni correction $(p=(0.05 / 5)=0.01)$, this correlation also did not survive (Fig. 5).

For the other three emotions; happiness, sadness, anger, and neutral faces, the psychopathic traits, CU traits, and aggressive tendencies did not correlate with any of the eye-tracking variables on any of the AOIs.

\section{Control analyses}

To check if our effects were not driven by the known significant differences in intelligence, ADHD comorbidity and medication use between groups, we undertook additional analyses. We regressed out full-scale intelligence (FSQ) from the model. The Spearman correlation between the total YPI score and the time to first fixation on the eyes was not significant anymore $(r=0.26$, $p=0.14)$. For the ASD group, the correlation was significant $(r=0.31, p=0.04)$, but did not survive Bonferroni correction $(p=0.05 / 5=0.01)$. The Spearman correlation between proactive aggression and time to first fixation on the eyes of fearful faces was not significant anymore ( $r=0.18, p=0.3$ ). Concluding, the regression of fullscale intelligence scores from the model did not change the directions of the effect and all Spearman correlation still did not survive correction for multiple comparison. Furthermore, we ran analyses to control for the effects of ADHD comorbidity and medication use (for details, see 


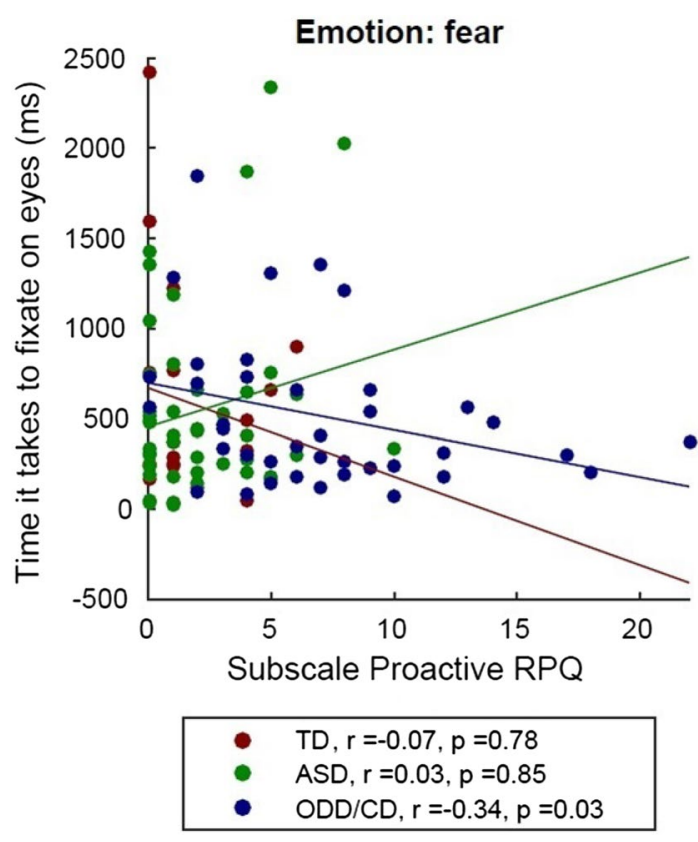

Fig. 5 Spearman correlations between the time to first fixation on the eyes of fearful faces and proactive aggression (RPQ- proactive subscale). $T D$ typically developing individuals, $A S D$ autism spectrum disorder, $O D D$ oppositional defiant disorder, $C D$ conduct disorder

supplementary Tables 2, 3, 4, and 5). In the sample, 50 (28 subjects with ODD/CD and 22 subjects with ASD) of the 122 subjects had a comorbid ADHD diagnosis, and in the case of 9 participants, information was missing. For both control analyses, we excluded those participants with either ADHD (or missing information) or on medication (or missing information).

The directions of the effects in both control analyses did not differ from the effects in the main analysis for total fixation duration, relative total fixation duration, and time to first fixation. Moreover, we ran control analysis for the Spearman correlation with behavioral traits (psychopathic traits and proactive aggression). In this case, we only selected participants without ADHD or that were not using medication (or missing information). The direction of the effects between the time to first fixation on the eyes of fearful faces in the ODD/CD group and psychopathic traits (YPI total score) and proactive aggression (RPQ proactive aggression subscale) did not change (see supplementary Table 5 for these results).

\section{Discussion}

This study aimed to investigate common cross disorder and unique disorder-specific patterns of eye gaze during emotional face processing by a head-to-head comparison of male adolescents with either ASD, or ODD/CD, compared to TD for eye-tracking measures (1) time to first fixation on an AIO, (2) total fixation duration to an AOI, and (3) percentage of total fixation duration on an AOI relative to the rest. We also examined the modulating role of $\mathrm{CU}$ and psychopathic traits, and aggression subtypes. We chose not to include subjects with a combined diagnosis of both ASD and ODD/CD to facilitate a clear crossdisorder comparison. In this way, we are not looking at the combined comorbid group (with a diagnosis of both ASD and ODD/CD) and cannot compare synergistic effects arising from the comorbidity of these disorders. Our results showed that (1) participants with either ASD or ODD/CD both did fixate proportionally and significantly less on the eye region of emotional faces (with sadness excepted) and neutral faces, compared to TD. (2) participants with either ASD or ODD/CD both took longer time to first fixation on the eye region in fearful faces, but not in faces with the other emotions/emotional expressions (i.e., neutral, anger, sadness, and happiness). However, this effect did not survive multiple comparison correction. (3) When looking at the relationship between eye gazing and CU traits, psychopathic traits, and aggression, we found a seemingly opposing effect. Higher scores for psychopathic traits and of proactive aggression within the ODD/CD group were nominally significant associated with shorter time to first fixation at the eye region for fearful faces compared to the TD group. All three groups were paying more attention to the eye region compared to the mouth region and other parts of the face. Since these effects did not survive multiple comparison and regressing out full-scale intelligence scores did not change this, we did not find solid evidence for the hypothesized relationships.

Some studies have indicated that excessive attention to the mouth region may be adaptive for ASD children with well-developed language skills [72]. More recent work falsifies the gaze aversion to the eyes in infants [59]. These findings are not confirmed in our high-functioning adolescent male population with ASD. The differential results can be explained by differences in methodology across laboratories and also the high heterogeneity in gazing behavior for individuals with ASD. The different age ranges of samples and their intelligence profiles may also partly explain differences in findings [41].

Earlier studies reported poorer recognition of emotional facial expressions in individuals with $\mathrm{CD}[36,87]$ and also abnormally low amygdala activations to fearful or angry emotional faces in individuals with $\mathrm{CD}$, particularly those with high CU traits $[50,67]$. We observed both in the $\mathrm{ODD} / \mathrm{CD}$ and ASD groups proportionally less gazing at the eye region of emotional and neutral faces. This suggests that less gazing at the eye region of emotional faces might still be a cross-disorder trait that is not unique to ASD, but shared with other disorders like ODD/CD, which 
is in line with findings that emotion recognition problems characterize a wide range of child psychiatric disorders, varying from $A S D, A D H D$, and $C D$ to mood and anxiety disorders and eating disorders and schizophrenia [23].

The novelty of our study is that we are providing insight into differences of eye-gazing behavior on fearful faces between clinical groups that are well-phenotyped and look at the links with psychopathic traits, CU traits, and aggression. We found that the time to first fixation is delayed for the ODD/CD group for the time to first fixating on the eyes of fearful faces. A delayed first fixation to fearful eyes might lead to slower processing and delayed evaluating of the fearful state of the other person. Small distortions in synchrony of emotional communication between individuals due to delayed processing of emotional information may already disrupt social interactions and predispose to inadequate and even harmful behavior [14, 53].

There was a nominally significant negative correlation in our ODD/CD group between the time to first fixation to the eyes of fearful faces and psychopathic personality traits (YPI). This effect did not survive multiple comparison correction. This dimensional effect concerning higher psychopathic traits is opposite the group effect of eye gazing in our ODD/CD participants that gaze later to the eyes of fearful faces. The absence of a relationship between psychopathic/ CU traits and gaze fixation in both the ASD group and the TD group might be due to the smaller variance in psychopathy and CU scores (for details, see Table 1) in these groups. It might be that a selection bias led to the oversampling of participants lower than average on psychopathic traits, $\mathrm{CU}$ traits, aggression for those that score average or high might be less willing to be subjected to testing in a clinical research setting.

In general, a modulating role of psychopathic traits is consistent with findings in functional MRI studies, where amygdala activation to fearful or angry faces is low in the presence of high psychopathic and high in their absence [50, 67]. Klapwijk et al. [51] also found decreased amygdala responses in both adolescents with ASD and individuals with $\mathrm{CD}$ and high $\mathrm{CU}$ traits. We also found a possible association with the severity of in particular proactive aggression and time to first fixation on the eyes of fearful faces. Children as well as adolescents and adults with ODD/CD and high levels of psychopathy/CU traits are more likely to have high levels of proactive aggression [26, 39]. Our data does seem to suggest a potential link between ODD/CD, high psychopathic traits, proactive aggression, and impaired fear processing.

Although we document similar patterns of abnormal gaze behavior to emotional faces in ASD and ODD/CD, the underlying mechanism might be disorder specific. There are three theories trying to explain abnormal emotional face processing in ASD. First, gazing at faces and eyes in particular may lead to increased (negatively valence) emotional responses in individuals with ASD and even found to be aversive [31]. Looking at the mouth is then just a byproduct of avoiding gazing at the eyes. Second, another theory poses that individuals with ASD cannot "read the language of the eyes", i.e., they do not understand visual information from the eyes which may be linked to problems in using a Theory of Mind [52]. The failure to use information from the eye region in combination with an ability to use visual information from the mouth for speech related processing is driving the deficit of excess fixation on the mouth and diminished fixation on the eyes. Third, another explanation is that individuals with ASD are suffering from impaired social orientation and that the "most social" part of the face, the eye region lacks saliency and does not arouse sufficient intrinsic interest to be looked at [41]. Unfortunately, our paradigm and our results not allow us to differentiate between these potential explanations.

Impaired affective responses and emotional processing in $\mathrm{CD}$ has been addressed by three main theories [32]. The attention to the eyes hypothesis proposes that emotion processing deficits in $\mathrm{CD} /$ psychopathy arise from a lack of spontaneous attention to the eye region $[30,28]$ which negatively affect the processing of all emotional expressions. The distress-specific hypothesis states that individuals with $\mathrm{CD} /$ psychopathy fail to effectively process in particular others' expressions of distress (fear and sadness). As a result, their antisocial actions are not inhibited by aversive feelings of remorse and guilt, resulting in callous behavior and shallow affect $[15,11]$. Finally, the enhanced selective attention hypothesis [63, 61, 62] states that the enhanced ability to focus on a task and to ignore goal irrelevant stimuli underlies affective deficits. This superior selective attention can enhance the top-down ability to suppress emotional information that is irrelevant to one's goals, for example, another person's distress if the psychopath wants to steal their money. Since the gaze pattern with proportionally less attention to the eye region was observed for all emotions except for sadness, our results are mostly in line with the attention to the eye hypothesis or the enhanced ability to focus hypothesis.

Our groups did not differ with respect to the total fixation duration on the eyes while processing sad faces. Other studies have shown that emotional recognition deficits for sadness are present in people with ODD/CD [79, 87]. These discrepant findings may be due to differences between studies in sample selection and characteristics. The Woodworth and Waschbusch [87] sample consisted of both male and female children with high levels of CU traits, which is quite different from our male adolescent sample. The Stevens et al.'s [79] sample did not use a formal clinical diagnosis of ODD or $\mathrm{CD}$ and selected participants on the basis of a score of 25 or higher on the psychopathy screening device [38]. 
Despite its strengths, such as the direct comparison of a well-powered ASD and ODD/CD group and its focus of gaze behavior by means of eye-tracking measures which ruled out the influence of social desired expected answers of questionnaires, our study also showed limitations. We were not able to control the gaze duration to the fixation cross prior to the faces that were portrayed on the screen. As half of our trials contained neutral faces, we did not have enough trials per emotion to look into the effects of gender, ethnicity, and the intensity effects of the emotions portrayed on the faces. The stimuli used in this study were selected from a validated database of emotional expressions: including stimuli with facial characteristics such as wrinkles and facial hair. Facial characteristics can be seen as a factor that may influence the study outcomes. In contrast to studies that use morphed faces, our facial stimuli are closer to emotional faces in the real world. On the other hand, this might potentially revert the attention of the participants and confound the outcome. Both diagnostic groups also contained a substantial amount of participants with comorbid ADHD and/or using medication. Although antipsychotics (where possible) were stopped 2 days before, and stimulants on the test day, we cannot rule out possible medication effects. However, sensitivity analyses revealed that results were not influenced by the presence of a comorbid diagnosis of ADHD or by medication use.

\section{Implications}

Considering the consequences of aggression, there is a need for a better understanding of underlying causes and maintaining factors. The current study contributes to the enhancement of this understanding by revealing (1) two cross-disorder traits for ASD and ODD/CD; (2) disorder-specific traits for $\mathrm{ODD} / \mathrm{CD}$ with proactive aggression as a potential factor. Future research is warranted to examine possible other crossdisorder traits (e.g., biological and genetic) and/or disorderspecific traits; and (3) adding to knowledge and understanding in fractioning empathy to emotional stimuli by means of eye-gazing processing as a part of the MATRICS project (http://matrics-project.eu/). MATRICS examines the neural, genetic, and molecular factors involved in the pathogenesis of aggression/antisocial behavior and that in relation with callous-unemotional traits.

Moreover, as the current treatments, which mainly involve skill training, are not suitable or developed to alter implicit characteristics, other methods are needed to improve the efficacy of aggression treatment, and techniques like virtual reality seem to be promising $[66,69]$. Clinical implications are mainly optimization of psychological interventions by therapists requiring eye-gazing information. A future study would definitely also benefit from the presentation of both static and dynamic faces as stimuli and comparing outcomes.

\section{Conclusions}

To conclude, we reported that male adolescents with ASD or ODD/CD looked less at the eyes in fearful, angry, happy, or neutral emotional expressions. They also took nominal significantly more time to first fixate on the eyes of fearful faces compared to TD. Those male adolescents with ODD/CD that exhibit faster first fixations on the eyes of fearful faces had nominal significant higher scores on psychopathic traits. Nevertheless, we did not find strong evidence that survived multiple comparisons to support that in ASD and ODD/ $\mathrm{CD}$ higher scores on CU traits, psychopathy, and aggression were related to eye gazing on the eyes of fearful faces. Our data do provide valuable and new insight into the gaze behavior distributions of ODD/CD and ASD groups when looking at the eyes of emotional faces.

Acknowledgements We would like to thank all of our participants, families, and legal guardians for their participation. We would like to thank everyone that helped facilitate the testing and provided information on all kinds of levels. Special thanks to Pierre Herpers and Evita Wiegers for their active role in the CU2 study. In general, we would not have been able to write this manuscript without the collaborative spirit of all that were involved.

Funding This work was supported by Karakter Child and Adolescent Psychiatry, by grants of the National Initiative Brain and Cognition (NIBC; 056-24-011 and 056-24-014, and the European Union 7th Framework programs AGGRESSOTYPE (602805) and MATRICS (EU FP7, 603016). This work was also supported by EU-AIMS (European Autism Interventions), which receives support from the Innovative Medicines Initiative Joint Undertaking under grant agreement no. 115300 , the resources of which are composed of financial contributions from the European Union's Seventh Framework Programme (grant FP7/2007-2013), from the European Federation of Pharmaceutical Industries and Associations companies' in-kind contributions, and from Autism Speaks.

\section{Compliance with ethical standards}

Conflict of interest CC.A.H. Bours, M.J. Bakker-Huvenaars, J. Tramper, N. Bielczyk, A. N. Baanders, K.S. Nijhof, N.N.J. LambregtsRommelse, P. Medendorp, and F. Scheepers declared to have no conflicts of interest. J.C. Glennon has been in the past 3 years a consultant to Boehringer Ingelheim $\mathrm{GmbH}$ on matters unrelated to this paper. Jan K Buitelaar has been in the past 3 years a consultant to/member of advisory board of/and/or speaker for Janssen Cilag BV, Eli Lilly, Lundbeck, Shire, Roche, Novartis, Medice, and Servier. He is not an employee of any of these companies, and not a stock shareholder of any of these companies. He has no other financial or material support, including expert testimony, patents, and royalties.

Open Access This article is distributed under the terms of the Creative Commons Attribution 4.0 International License (http://creativeco mmons.org/licenses/by/4.0/), which permits unrestricted use, distribution, and reproduction in any medium, provided you give appropriate credit to the original author(s) and the source, provide a link to the Creative Commons license, and indicate if changes were made. 


\section{References}

1. American Psychiatric Association (2013) Diagnostic and statistical manual of mental disorders (5th edn)

2. Andershed HA, Kerr M, Stattin H, Levander S (2002) Psychopathic traits in non-referred youths: a new assessment tool. Psychopaths: current international perspectives. Elsevier, Den Haag, pp 131-158

3. APA (2013) Autism, psychology topics

4. Ashwin C, Chapman E, Colle L, Baron-Cohen S (2006) Impaired recognition of negative basic emotions in autism: a test of the amygdala theory. Soc Neurosci 1(3-4):349-363. https://doi. org/10.1080/17470910601040772

5. Association, A. P. (2000) Diagnostic criteria from dsm-iv-tr. American Psychiatric Pub

6. Bal E, Harden E, Lamb D, Van Hecke AV, Denver JW, Porges SW (2010) Emotion recognition in children with autism spectrum disorders: relations to eye gaze and autonomic state. J Autism Dev Disord 40:358-370. https://doi.org/10.1007/s10803-009-0884-3

7. Bal E, Harden E, Lamb D, Van Hecke AV, Denver JW, Porges SW (2010) Emotion recognition in children with autism spectrum disorders: relations to eye gaze and autonomic state. J Autism Dev Disord 40(3):358-370. https://doi.org/10.1007/s10803-009-0884-3

8. Berument SK, Rutter M, Lord C, Pickles A, Bailey A, Kazak S, Bailey A (1999) Autism screening questionnaire: diagnostic validity Autism screening questionnaire: diagnostic validity. Br J Psychiatry 175:444-451. https://doi.org/10.1192/bjp.175.5.444

9. Biederman J, Faraone SV, Milberger S, Jetton JG, Chen L, Mick E, Russell RL (1996) Is childhood oppositional defiant disorder a precursor to adolescent conduct disorder? Findings from a four-year follow-up study of children with ADHD. J Am Acad Child Adolesc Psychiatry 35(9):1193-1204. https://doi. org/10.1097/00004583-199609000-00017

10. Blair, Coles (2000) Expression recognition and behavioural problems in early adolescence. Cognit Dev 15(4):421-434. https://doi. org/10.1016/S0885-2014(01)00039-9

11. Blair RJR (1995) A cognitive developmental approach to morality: investigating the psychopath. Cognition 57(1):1-29. https://doi. org/10.1016/0010-0277(95)00676-P

12. Blair RJR (2003) Neurobiological basis of psychopathy Neurobiological basis of psychopathy. Br J Psychiatry 1(182):5-7. https ://doi.org/10.1192/bjp.182.1.5

13. Blair RJR (2013) The neurobiology of psychopathic traits in youths. Nat Rev Neurosci 14(11):786-799. https://doi. org/10.1038/nrn3577

14. Blair RJR, Colledge E, Murray L, Mitchell DGV (2001) A selective impairment in the processing of sad and fearful expressions in children with psychopathic tendencies. J Abnorm Child Psychol 29(6):491-498. https://doi.org/10.1023/A:1012225108281

15. Blair RJR, Peschardt KS, Budhani S, Mitchell DGV, Pine DS (2006) The development of psychopathy. J Child Psychol Psychiatry 47(3-4):262-275. https://doi.org/10.111 1/j.1469-7610.2006.01596.x

16. Blair R, Mitchell D, Blair K (2005) The psychopath: emotion and the brain. Blackwell Publishing Ltd, London

17. Blais J, Solodukhin E, Forth AE (2014) A meta-analysis exploring the relationship between psychopathy and instrumental versus reactive violence. Crim Just Behav 41(7):797-821. https://doi. org/10.1177/0093854813519629

18. Breslow N (1970) A generalized Kruskal-Wallis test for comparing $\mathrm{K}$ samples subject to unequal patterns of censorship. Biometrika 579-594

19. Chandler S, Charman T, Baird G, Simonoff E, Loucas T, Meldrum D, Pickles A (2007) Validation of the social communication questionnaire in a population cohort of children with autism spectrum disorders. J Am Acad Child Adolesc Psychiatry 46(10):13241332. https://doi.org/10.1097/chi.0b013e31812f7d8d

20. Chatham $\mathrm{CH}$, Taylor KI, Charman T, Liogier D'ardhuy X, Eule E, Fedele A, Bolognani F (2017) Adaptive behavior in autism: minimal clinically important differences on the Vineland-II. Aut Res. https://doi.org/10.1002/aur.1874

21. Chita-Tegmark M (2016) Attention allocation in ASD: a review and meta-analysis of eye-tracking studies. Rev J Aut Dev Disord 3(3):209-223. https://doi.org/10.1007/s40489-016-0077-x

22. Cima M, Raine A, Meesters C, Popma A (2013) Validation of the Dutch Reactive Proactive Questionnaire (RPQ): differential correlates of reactive and proactive aggression from childhood to adulthood. Aggress Behav 39(2):99-113. https://doi.org/10.1002/ ab. 21458

23. Collin L, Bindra J, Raju M, Gillberg C, Minnis H (2013) Facial emotion recognition in child psychiatry: a systematic review. Res Dev Disabil 34(5):1505-1520. https://doi.org/10.1016/j. ridd.2013.01.008

24. Cooke DJ, Michie C (2001) Refining the construct of psychopathy: towards a hierarchical model. Psychol Assess 13(2):171

25. Corden B, Chilvers R, Skuse D (2008) Avoidance of emotionally arousing stimuli predicts social-perceptual impairment in Asperger's syndrome. Neuropsychologia 46:137-147. https:// doi.org/10.1016/j.neuropsychologia.2007.08.005

26. Cornell DG, Warren J, Hawk G, Stafford E, Oram G, Pine D (1996) Psychopathy in instrumental and reactive violent offenders. J Consult Clin Psychol 64(4):783-790. https://doi. org/10.1037/0022-006X.64.4.783

27. Cuff BMP, Brown SJ, Taylor L, Howat DJ (2016) Empathy: a review of the concept. Emotion Review 8(2):144-153. https://doi. org/10.1177/1754073914558466

28. Dadds MR, Allen JL, McGregor K, Woolgar M, Viding E, Scott $S$ (2014) Callous-unemotional traits in children and mechanisms of impaired eye contact during expressions of love: a treatment target? J Child Psychol Psychiatry 55(7):771-780. https://doi. org/10.1111/jcpp.12155

29. Dadds MR, El Masry Y, Wimalaweera S, Guastella AJ (2008) Reduced eye Gaze Explains "Fear Blindness" in childhood psychopathic traits. J Am Acad Child Adolesc Psychiatry 47(4):455463. https://doi.org/10.1097/CHI.0b013e31816407f1

30. Dadds MR, Perry Y, Hawes DJ, Merz S, Riddell AC, Haines DJ, Abeygunawardane AI (2006) Attention to the eyes and fear-recognition deficits in child psychopathy. Br J Psychiatry 189(SEP.):280-281. https://doi.org/10.1192/bjp.bp.105.018150

31. Dalton KM, Nacewicz BM, Johnstone T, Schaefer HS, Gernsbacher MA, Goldsmith HH, Davidson RJ (2005) Gaze fixation and the neural circuitry of face processing in autism. Nat Neurosci 8(4):519-526. https://doi.org/10.1038/nn1421

32. Dawel A, McKone E, O'Kearney R, Sellbom M, Irons J, Palermo R (2015) elevated levels of callous unemotional traits are associated with reduced attentional cueing, with no specificity for fear or eyes. Personal Disord 6(3):216-228. https://doi.org/10.1037/ per0000108

33. Dawel A, O'Kearney R, McKone E, Palermo R (2012) Not just fear and sadness: meta-analytic evidence of pervasive emotion recognition deficits for facial and vocal expressions in psychopathy. Neurosci Biobehav Rev 36(10):2288-2304. https://doi. org/10.1016/j.neubiorev.2012.08.006

34. Decuyper M, De Clercq B, De Bolle M, De Fruyt F (2009) Validation of FFM PD COUNTS for screening personality pathology and psychopathy in adolescence. J Pers Disord 23(6):587-605. https://doi.org/10.1521/pedi.2009.23.6.587

35. Fairchild G, Stobbe Y, Van Goozen SHM, Calder AJ, Goodyer IM (2010) Facial expression recognition, fear conditioning, and startle modulation in female subjects with conduct disorder. 
Biol Psychiat 68(3):272-279. https://doi.org/10.1016/j.biops ych.2010.02.019

36. Fairchild G, Van Goozen SHM, Calder AJ, Stollery SJ, Goodyer IM (2009) Deficits in facial expression recognition in male adolescents with early-onset or adolescence-onset conduct disorder. J Child Psychol Psychiatry 50(5):627-636. https://doi.org/10.11 11/j.1469-7610.2008.02020.x

37. Frick P (2004) The inventory of callous-unemotional traits. Unpublished Rating Scale

38. Frick PJ, Hare RD (2001) The psychopathy screening device. Multi-Health Systems, Toronto

39. Frick PJ, Kimonis ER, Dandreaux DM, Farell JM (2003) The 4 year stability of psychopathic traits in non-referred youth. Behav Sci Law 21(6):713-736. https://doi.org/10.1002/bsl.568

40. Groth-Marnat, G. (1997). Millon clinical multiaxial inventory. Handbook of Psychological Assessment, pp 301-342

41. Guillon Q, Hadjikhani N, Baduel S, Rogé B (2014) Visual social attention in autism spectrum disorder: insights from eye tracking studies. Neurosci Biobehav Rev 42:279-297. https://doi. org/10.1016/j.neubiorev.2014.03.013

42. Gur RC, Sara R, Hagendoorn M, Marom O, Hughett P, Macy L, Gur RE (2002) A method for obtaining 3-dimensional facial expressions and its standardization for use in neurocognitive studies. J Neurosci Methods 115(2):137-143

43. Hernandez N, Metzger A, Magné R, Bonnet-Brilhault F, Roux S, Barthelemy C, Martineau J (2009) Exploration of core features of a human face by healthy and autistic adults analyzed by visual scanning. Neuropsychologia 47:1004-1012. https://doi. org/10.1016/j.neuropsychologia.2008.10.023

44. Herpers PCM, Klip H, Rommelse NNJ, Greven CU, Buitelaar JK (2016) Associations between high callous-unemotional traits and quality of life across youths with non-conduct disorder diagnoses. Eur Child Adolesc Psychiatry 25(5):547-555. https://doi. org/10.1007/s00787-015-0766-5

45. Herpers PCM, Rommelse NNJ, Bons DMA, Buitelaar JK, Scheepers FE (2012) Callous-unemotional traits as a cross-disorders construct. Soc Psychiatry Psychiatr Epidemiol 47(12):2045-2064. https://doi.org/10.1007/s00127-012-0513-x

46. Herpers PCM, Scheepers FE, Bons DMA, Buitelaar JK, Rommelse NNJ (2014) The cognitive and neural correlates of psychopathy and especially callous-unemotional traits in youths: a systematic review of the evidence. Dev Psychopathol 26(1):245273. https://doi.org/10.1017/S0954579413000527

47. Hill AP, Zuckerman KE, Hagen AD, Kriz DJ, Duvall SW, Van Santen J, Fombonne E (2014) Aggressive behavior problems in children with autism spectrum disorders: prevalence and correlates in a large clinical sample. Res Autism Spectr Disord 8(9):1121-1133. https://doi.org/10.1016/j.rasd.2014.05.006

48. Howard MA, Cowell PE, Boucher J, Broks P, Mayes A, Farrant A, Roberts N (2000) Convergent neuroanatomical and behavioural evidence of an amygdala hypothesis of autism. NeuroReport 11(13):2931-2935. https://doi.org/10.1097/00001756-20000 9110-00020

49. Jones AP, Happé FGE, Gilbert F, Burnett S, Viding E (2010) Feeling, caring, knowing: different types of empathy deficit in boys with psychopathic tendencies and autism spectrum disorder. J Child Psychol Psychiatry 51(11):1188-1197. https://doi.org/10. 1111/j.1469-7610.2010.02280.x

50. Jones AP, Laurens KR, Herba CM, Barker GJ, Viding E (2009) Amygdala hypoactivity to fearful faces in boys with conduct problems and callous-unemotional traits. Am J Psychiatry 166(January):95-102. https://doi.org/10.1176/appi.ajp.2008.07071050

51. Klapwijk ET, Aghajani M, Colins OF, Marijnissen GM, Popma A, Van Lang NDJ, Vermeiren RRJM (2016) Different brain responses during empathy in autism spectrum disorders versus conduct disorder and callous-unemotional traits. J Child Psychol Psychiatry 57(6):737-747. https://doi.org/10.1111/jcpp.12498

52. Klin A, Jones W, Schultz R, Volkmar F, Cohen D (2002) Defining and quantifying the social phenotype in autism. Am J Psychiatry 159(6):895-908. https://doi.org/10.1176/appi.ajp.159.6.895

53. Klin A, Jones W, Schultz R, Volkmar F, Cohen D (2002) Visual fixation patterns during viewing of naturalistic social situations as predictors of social competence in individuals with autism. Arch Gen Psychiatry 59(9):809-816. https://doi.org/10.1001/archp syc.59.9.809

54. Leckman J, Sholomskas D, Thompson D, Belanger A, Weissman M (1982) Best estimate of lifetime psychiatric diagnosis: a methodological study. Arch Gen Psychiatry 39(8):879-883. https ://doi.org/10.1001/archpsyc.1982.04290080001001

55. Leno C, Charman T, Pickles A, Jones CRG, Baird G, Happe F, Simonoff E (2015) Callous-unemotional traits in adolescents with autism spectrum disorder. Br J Psychiatry. https://doi.org/10.1192/ bjp.bp.114.159863

56. Marsh AA, Blair RJR (2008) Deficits in facial affect recognition among antisocial populations: a meta-analysis. Neurosci Biobehav Rev 32(3):454-465. https://doi.org/10.1016/j.neubi orev.2007.08.003

57. Martin-Key NA, Graf EW, Adams WJ, Fairchild G (2017) Facial emotion recognition and eye movement behaviour in conduct disorder. J Child Psychol Psychiatry. https://doi.org/10.1111/ jcpp. 12795

58. Matheworks T (2016) Matlab 2016B. MA, Natick

59. Moriuchi JM, Klin A, Jones W (2017) Mechanisms of diminished attention to eyes in Autism. Am J Psychiatry 174(1):26-35. https ://doi.org/10.1176/appi.ajp.2016.15091222

60. Nakano T, Tanaka K, Endo Y, Yamane Y, Yamamoto T, Nakano Y, Ozonoff S (2010) Atypical gaze patterns in children and adults with autism spectrum disorders dissociated from developmental changes in gaze behaviour. Proc Biol Sci R Soc 277(1696):29352943. https://doi.org/10.1098/rspb.2010.0587

61. Newman JP, Curtin JJ, Bertsch JD, Baskin-Sommers AR (2010) Attention moderates the fearlessness of psychopathic offenders. Biol Psychiat 67(1):66-70. https://doi.org/10.1016/j.biops ych.2009.07.035

62. Newman JP, Lorenz AR, Davidson RJ (2003) Response modulation and emotion processing: implications for psychopathy and other dysregulatory psychopathology. In: Handbook of Affective Sciences, pp 904-929. Oxford University Press, New York. Date 23 July 2013

63. Newman JP, Schmitt WA (1998) Passive avoidance in psychopathic offenders: a replication and extension. J Abnorm Psychol 107(3):527-532. https://doi.org/10.1037/0021-843X.107.3.527

64. Papagiannopoulou EA, Chitty KM, Hermens DF, Hickie IB, Lagopoulos J (2014) A systematic review and meta-analysis of eye-tracking studies in children with autism spectrum disorders. Soc Neurosci. https://doi.org/10.1080/17470919.2014.934966

65. Pasalich DS, Dadds MR, Hawes DJ (2014) Cognitive and affective empathy in children with conduct problems: additive and interactive effects of callous-unemotional traits and autism spectrum disorders symptoms. Psychiatry Res 219(3):625-630. https://doi. org/10.1016/j.psychres.2014.06.025

66. Paschall MJ, Fishbein DH, Hubal RC, Eldreth D (2005) Psychometric properties of virtual reality vignette performance measures: a novel approach for assessing adolescents' social competency skills. Health Educ Res 20(1):61-70. https://doi.org/10.1093/her/ cyg 103

67. Passamonti L, Fairchild G, Goodyer IM, Hurford G, Hagan CC, Rowe JB, Calder AJ (2010) Neural abnormalities in earlyonset and adolescence-onset conduct disorder. Arch Gen Psychiatry 67(7):729-738. https://doi.org/10.1001/archgenpsychiat ry. 2010.75 
68. Pelphrey KA, Sasson NJ, Reznick JS, Paul G, Goldman BD, Piven (2002) Visual scanning of faces in autism. J Aut Dev Disord 32(4):249-261

69. Persky S, McBride CM (2009) Immersive virtual environment technology: a promising tool for future social and behavioral genomics research and practice. Health Commun 24(8):677-682. https://doi.org/10.1080/10410230903263982

70. Pijper J, de Wied M, van Rijn S, van Goozen S, Swaab H, Meeus W (2016) Callous unemotional traits, autism spectrum disorder symptoms and empathy in boys with oppositional defiant disorder or conduct disorder. Psychiatry Res 245:340-345. https://doi. org/10.1016/j.psychres.2016.08.053

71. Raine A, Weiss E, Kohler C, Nolan K, Czobor P, Volavka J, Gur $\mathrm{R}$ (2006) The relationship between history of violent and criminal behavior and recognition of facial expression of emotions in men with schizophrenia and schizoaffective disorder. Aggress Behavour 32(3): 187-194

72. Rice K, Moriuchi JM, Jones W, Klin A (2012) Parsing heterogeneity in ASD: visual scanning of dynamic social scenes in schoolaged children. J Am Acad Child Adolesc Psychiatry Psychiatry 51(3):238-248. https://doi.org/10.1016/j.jaac.2011.12.017.Parsi ng

73. Rogers J, Viding E, James Blair R, Frith U, Happé F (2006) Autism spectrum disorder and psychopathy: shared cognitive underpinnings or double hit? Psychol Med 36(12):1789. https:// doi.org/10.1017/S0033291706008853

74. Roose A, Bijttebier P, Decoene S, Claes L, Frick PJ (2010) Assessing the affective features of psychopathy in adolescence: a further validation of the inventory of callous and unemotional traits. Assessment 17(1):44-57. https://doi.org/10.1177/1073191109 344153

75. Rutter M, Le Couteur A, Lord C (2003) ADI-R. Autism diagnostic interview revised. Manual. Western Psychological Services, Los Angeles

76. Schwenck C, Mergenthaler J, Keller K, Zech J, Salehi S, Taurines R, Freitag CM (2012) Empathy in children with autism and conduct disorder: group-specific profiles and developmental aspects. J Child Psychol Psychiatry 53(6):651-659. https://doi.org/10.11 11/j.1469-7610.2011.02499.x

77. Shaffer D, Fisher P, Lucas C, Dulcan M, Schwab-Stone M (2000) NIMH Diagnostic Interview Schedule for Children, Version IV
(NIMH DISC-IV): description, differences from previous versions, and reliability of some common diagnoses. J Am Acad Child Adolesc Psychiatry 39:28-38

78. Speer LL, Cook AE, McMahon WM, Clark E (2007) Face processing in children with autism: effects of stimulus contents and type. Autism 11(3):265-277. https://doi.org/10.1177/1362361307 076925

79. Stevens D, Charman T, Blair RJ (2001) Recognition of emotion in facial expressions and vocal tones in children with psychopathic tendencies. J Genetic Psychol 162(2):201-211. https://doi. org/10.1080/00221320109597961

80. Sully K, Sonuga-Barke EJS, Fairchild G (2015) The familial basis of facial emotion recognition deficits in adolescents with conduct disorder and their unaffected relatives. Psychol Med 45(09):19651975. https://doi.org/10.1017/S0033291714003080

81. Tottenham N, Tanaka JW, Leon AC, McCarry T,Nurse M, Hare TA, Nelson C (2009) The NimStim set of facial expressions: judgements from untrained research participants. Psychiatry Res 168(3):242-249. https://doi.org/10.1016/j.psychres.2008.05.006

82. Van Der Geest JN, Kemner C, Verbaten MN, Van Engeland H (2002) Gaze behavior of children with pervasive developmental disorder toward human faces: a fixation time study. J Child Psychol Psychiatry 43(5):669-678. https://doi. org/10.1111/1469-7610.00055

83. Wagner JB, Hirsch SB, Street A, Nelson CA (2014) Eye-tracking, autonomic, and electrophysiological correlates of emotional face processing in adolescents with autism spectrum disorder. J Autism Dev Disord 43(1):188-199. https://doi.org/10.1007/s10803-0121565-1.Eye-Tracking

84. Wallace S, Coleman M, Bailey A (2008) An investigation of basic facial expression recognition in autism spectrum disorders. Cogn Emot 22(7):1353-1380. https://doi.org/10.1080/0269993070 1782153

85. Wechsler D (1991) Manual for the Wechsler intelligence scale for children-(WISC-III). Psychological Corporation, San Antonio

86. Wechsler D (1997) WAIS-III: Wechsler adult intelligence scale. Psychological Corporation

87. Woodworth M, Waschbusch D (2008) Emotional processing in children with conduct problems and callous/unemotional traits. Child Care Health Dev 34(2):234-244. https://doi.org/10.111 1/j.1365-2214.2007.00792.x

\section{Affiliations}

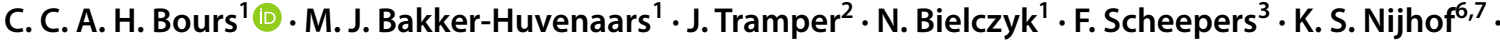 A. N. Baanders ${ }^{5}$. N. N. J. Lambregts-Rommelse ${ }^{4,8} \cdot$ P. Medendorp ${ }^{2} \cdot$ J. C. Glennon ${ }^{1}$ - J. K. Buitelaar ${ }^{1,4}$}

1 Department of Cognitive Neuroscience, Donders Institute for Brain, Cognition and Behavior, Radboud University Medical Centre, Nijmegen, The Netherlands

2 Centre for Cognition, Donders Institute for Brain, Cognition and Behavior, Radboud University, Nijmegen, The Netherlands

3 Brain Center Rudolf Magnus, UMC Utrecht, Utrecht, The Netherlands

4 Karakter Child and Adolescent Psychiatry University Centre Nijmegen, Nijmegen, The Netherlands

5 Stichting Otto Gerhard Heldring, Zetten, The Netherlands
6 Pluryn, Hoenderloo, The Netherlands

7 Department of Developmental Psychology, Radboud University, Nijmegen, The Netherlands

8 Department of Psychiatry, Donders Institute for Brain, Cognition and Behavior, Radboud University Medical Centre, Nijmegen, The Netherlands 